\title{
AVALIAÇÃO DA QUALIDADE DA INFORMAÇÃO EM UMA EMPRESA DO SETOR METAL-MECÂNIICO
}

\section{EVALUATION OF THE INFORMATION QUALITY IN A COMPANY OF METAL- MECHANICAL INDUSTRY}

\author{
Guilherme Augusto Spiegel Gualazzi* E-mail: gualazzi@adafa.org.br \\ Fernando Celso de Campos* E-mail: fccampos@unimep.br \\ *Universidade Metodista de Piracicaba (UNIMEP), Piracicaba, SP
}

\begin{abstract}
Resumo: Este trabalho apresenta a aplicação de um instrumento de avaliação da qualidade da informação com base em atributos, como acurácia, confiabilidade, apresentação, entre outros. $O$ referido instrumento foi aplicado no intuito de avaliar e identificar informações inefetivas em um cenário específico de engenharia de uma empresa do setor metal-mecânico, sob o ponto de vista de usuários de informações técnicas. O estudo de caso teve por objetivo atestar a aplicabilidade e funcionalidade do instrumento de avaliação, o interesse das pessoas em avaliar suas informações e, finalmente, avaliar o alcance de seus resultados. O resultado desta avaliação permitiu que a empresa pesquisada traçasse um plano de ação no sentido de corrigir problemas em seus processos e incorreções identificadas nas informações, indicando que o problema foi sanado por meio de método de solução de problemas.
\end{abstract}

Palavras-chave: Perspectivas de Qualidade. Atributos de Qualidade. Qualidade da Informação. Solução de Problemas. Instrumento de Avaliação.

Abstract:This paper presents the application of an instrument for assessing the quality of information based on attributes such as accuracy, reliability, performance, among others. This instrument was applied in order to evaluate and identify ineffective information in a specific scenario of an engineering company in the metal-mechanic sector from the point of view of users of technical information. The case study aimed to demonstrate the applicability and functionality of the assessment instrument, the interest of people in evaluating their information and, finally, evaluate the scope of their results. The result of this evaluation allowed the company researched a plan of action to correct problems in its processes and identified inaccuracies in the information, indicating that the problem was solved by the method of problem solving.

Keywords: Perspective of Quality. Quality Attributes. Information Quality. Problem Solving. Assessment Instrument.

\section{INTRODUÇÃO}

Sabendo-se que a produção da informação tem relação com o trato matemático-estatístico ou analítico, a informação gerada, produto final do processo, será o reflexo dessa produção. Um determinado dado que traduz uma realidade traz consigo um componente de informação que extrapola sua forma. Esse mesmo dado 
implica rigoroso tratamento para se atingir a credibilidade da fonte que o divulga. A informação, derivada deste mesmo dado, permitirá as mais diversas interpretações por parte de todos os envolvidos no cenário de decisão no qual a informação foi utilizada. Um dado pode não representar uma realidade ou não ter nenhum sentido para um usuário e, ao mesmo tempo, trazer consigo um significado, fazendo com que essa informação seja qualitativamente diferente, vinculada ao seu respectivo gerador e ao usuário.

Assim, a questão que permeia a informação transfere a discussão para além da simples construção do dado: leva às questões da informação gerada com o dado, questionamentos sobre qualidade da informação e sua utilidade para o usuário.

Os diferentes cenários e decisores - junto com seus pesos e critérios - fazem com que as fontes geradoras de informação forneçam informações cada vez mais customizadas, tornando-as valiosas por seus atributos. Conseqüentemente, o resultado das decisões tomadas com base nessas informações reflete o seu verdadeiro valor. Assim, como é possível saber se uma informação é adequada a um cenário de decisão? Afinal, descobrir que a informação era inefetiva a um cenário de decisão após ter sido utilizada, só faz aumentar os problemas.

Dentro dessa perspectiva, no presente estudo, o assunto é a avaliação da qualidade da informação, a partir das expectativas e percepções dos usuários e gestores da informação.

A concepção de um instrumento de avaliação da qualidade da informação referenciada daqui em diante como QI - deve se cercar de algumas questões quanto à prática de seu uso, a fim de dar maior consistência ao instrumento. Sendo assim, surge o problema:

- É possível identificar informações inefetivas por meio de um instrumento de avaliação da qualidade?

Assim, este estudo teve por objetivo geral aplicar um instrumento de avaliação da QI em um cenário específico de uma empresa do setor metalmecânico, analisar os resultados e apontar melhorias dessas informações e suas fontes geradoras.

Este trabalho se restringe a comprovar a efetividade do instrumento de avaliação da qualidade da informação aplicando-o em uma empresa do setor metalmecânico. No entanto, apesar desta delimitação, propõe-se que o instrumento seja Revista Produção Online, Florianópolis, SC, v.12, n. 4, p. 1084-1105, out./dez. 2012. 
aplicado na avaliação de informações originadas de diferentes fontes, de qualquer segmento econômico, a fim de indicar manutenções que as adequem às reais necessidades de seus usuários.

Este artigo está estruturado no seguinte formato: na seção 1, o trabalho é apresentado, bem como seu contexto e relevância; a seção 2 trata da fundamentação teórica relacionada à revisão da literatura sobre qualidade da informação; a seção 3 apresenta o instrumento de avaliação da QI; a seção 4 trata da metodologia utilizada no estudo; na seção 5 é apresentada a aplicação do instrumento de avaliação da QI, os resultados e a análise dos resultados do estudo de caso; por último, a seção 6 apresenta as considerações finais deste trabalho.

\section{QUALIDADE DA INFORMAÇÃO}

Li \& Lin (2006) afirmam que a qualidade da informação contribui positivamente para a satisfação dos clientes e para a qualidade de parcerias de negócio ao longo da cadeia de suprimentos. Sellito et al. (2007) afirmam que as conseqüências de se ter informações de qualidade refletem-se na tomada de decisão de diversos negócios com bons resultados por toda a organização.

Segundo Miller et al. (2001), a informação pode ser vista como um bem, com dimensões e atributos de qualidade que podem ser medidas. Uma vez identificados os atributos, a qualidade da informação pode ser gerenciada.

Diversos estudos têm identificado vários atributos de QI, destaquem-se Ballou \& Pazer (1985), DeLone \& McLean (1992), Goodhue (1995), Wang \& Strong (1996), Lee, Strong, Khan \& Wang (2002) e outros já citados. Wand \& Wang (1996), por exemplo, afirmam que a qualidade da informação é um conceito multidimensional, e assim como um produto físico tem dimensões de qualidade associadas, um produto de informação também tem dimensões de qualidade.

Autores como Wang et al. (1995), Wang \& Strong (1996), Strong et al. (1997), Lee et al. (2002) e Pipino et al. (2002) desenvolveram uma sumarização das dimensões de qualidade apresentadas em estudos anteriores. Uma linha comum ao longo dessas referências é o uso de quatro dimensões para capturar os possíveis atributos de qualidade da informação (WANG \& STRONG, 1996): (1) a dimensão intrínseca (acurácia, credibilidade, objetividade, precisão e confiabilidade); (2) a 
dimensão contextual (relevância, oportunidade, completude e conveniência); (3) a dimensão de representação (compreensão, interpretabilidade, representação concisa e consistente), e; (4) a dimensão de acessibilidade (acessibilidade, segurança, disponibilidade do sistema, facilidade de operação e privilégios).

Durante os estudos sobre dimensões e atributos de QI observou-se que os autores pesquisados apresentam diferentes atributos de qualidade em suas obras. Sobre esse assunto, desenvolveu-se o Quadro 1.

Quadro 1 - Atributos de QI apresentados por diferentes autores

\begin{tabular}{|c|c|}
\hline Atributos & Bibliografia \\
\hline Prontidão / pontualidade & Stair \& Reynolds (2011); O’Brien (2004) \\
\hline $\begin{array}{l}\text { Aceitação; Atualidade; Apresentação; } \\
\text { Mídia; Integridade; Validade }\end{array}$ & Paim et al. (1996); O’Brien (2004) \\
\hline Freqüência; Detalhe & Bio (1996); O’Brien (2004) \\
\hline Período; Desempenho; Clareza; Ordem & O’Brien (2004) \\
\hline Precisão & Paim et al. (1996); English (2001); Stair \& Reynolds (2011); O’Brien (2004) \\
\hline Relevância/por exceção & $\begin{array}{l}\text { Bio (1996); Paim et al. (1996); Wang \& Strong (1996); English (2001); Stair } \\
\text { \& Reynolds (2011); Khan et al. (2002); Lillrank (2003); O'Brien (2004); Dai } \\
\text { et al. (2007) }\end{array}$ \\
\hline Concisão & Wang \& Strong (1996); Khan et al. (2002); Lillrank (2003); O’Brien (2004) \\
\hline Amplitude; flexibilidade; abrangência & Paim et al. (1996); Stair \& Reynolds (2011); O’Brien (2004) \\
\hline Completude & $\begin{array}{l}\text { Paim et al. (1996); Wang \& Strong (1996); English (2001); Stair \& } \\
\text { Reynolds (2011); Khan et al. (2002); Lillrank (2003) }\end{array}$ \\
\hline Economia / eficácia & Paim et al. (1996); Stair \& Reynolds (2011) \\
\hline Confiabilidade & Bio (1996); Paim et al. (1996); Stair \& Reynolds (2011); Lillrank (2003) \\
\hline Simplicidade & Stair \& Reynolds (2011); \\
\hline Verificável / comparável & Bio (1996); Stair \& Reynolds (2011) \\
\hline Acessível & $\begin{array}{l}\text { Wang \& Strong (1996); Stair \& Reynolds (2011); Khan et al. (2002); } \\
\text { Lillrank (2003); Dai et al. (2007) }\end{array}$ \\
\hline Segurança & $\begin{array}{l}\text { Wang \& Strong (1996); Khan et al. (2002); Stair \& Reynolds (2011); } \\
\text { Lillrank (2003) }\end{array}$ \\
\hline No contexto & English (2001); Lillrank (2003) \\
\hline Acurácia & Wang \& Strong (1996); English (2001); Lillrank (2003); Dai et al. (2007) \\
\hline Sem redundância & Paim et al. (1996); English (2001) \\
\hline Formato & Bio (1996); English (2001); O’Brien (2004) \\
\hline No lugar certo; Para o propósito certo & English (2001) \\
\hline $\begin{array}{l}\text { Valor filosófico ou metafísico; Novidade; } \\
\text { Significado através do tempo }\end{array}$ & Paim et al. (1996) \\
\hline Valor percebido / valor agregado & $\begin{array}{l}\text { Wang \& Strong (1996); Paim et al. (1996); Khan et al. (2002); Lillrank } \\
(2003)\end{array}$ \\
\hline Oportunidade & Wang \& Strong (1996); Khan et al. (2002); Lillrank (2003); Dai et al. (2007) \\
\hline $\begin{array}{l}\text { Adequação; Privacidade; Legalidade; } \\
\text { Disponibilidade }\end{array}$ & Dai et al. (2007) \\
\hline $\begin{array}{l}\text { Reputação; Quantidade de dados; } \\
\text { Interpretabilidade; Facilidade de } \\
\text { entendimento; Representação } \\
\text { consistente }\end{array}$ & Wang \& Strong (1996); Khan et al. (2002); Lillrank (2003) \\
\hline Credibilidade & Wang \& Strong (1996); Khan et al. (2002) \\
\hline $\begin{array}{l}\text { Facilidade de manipulação; Livre de } \\
\text { erro; Objetividade }\end{array}$ & Khan et al. (2002) \\
\hline
\end{tabular}

De acordo com a revisão da literatura, no que tange os atributos apresentados pelos diferentes autores, parece razoável compilar uma versão mais Revista Produção Online, Florianópolis, SC, v.12, n. 4, p. 1084-1105, out./dez. 2012. 
enxuta de uma lista de atributos de qualidade, a fim de utilizá-la como referência para a avaliação da QI. Assim, é apresentado o Quadro 2.

\begin{tabular}{|c|c|c|}
\hline Dimensão & Atributos de Qualidade & Definição \\
\hline \multirow{4}{*}{ Tempo } & Prontidão/Pontualidade & $\begin{array}{l}\text { A informação deve ser fornecida quando for necessária. Uma } \\
\text { informação deve estar tão próxima do acontecimento quanto for } \\
\text { possível }\end{array}$ \\
\hline & Atualização & A informação deve estar atualizada quando for fornecida. \\
\hline & Freqüência & $\begin{array}{l}\text { A informação deve ser fornecida tantas vezes quantas forem } \\
\text { necessárias. }\end{array}$ \\
\hline & Período & $\begin{array}{l}\text { A informação pode ser fornecida sobre períodos passados, } \\
\text { presentes e futuros. }\end{array}$ \\
\hline \multirow{11}{*}{ Conteúdo } & Precisão/correção & A informação deve estar isenta de erros. \\
\hline & Relevância/por exceção & $\begin{array}{l}\text { A informação deve estar relacionada às necessidades de } \\
\text { informação de um receptor específico para uma situação } \\
\text { específica. Deve ser destacado o que é relevante, as exceções. }\end{array}$ \\
\hline & Integridade & Toda a informação que for necessária deve ser fornecida. \\
\hline & Completude & A informação completa contém todos os fatos importantes. \\
\hline & Concisão & Apenas a informação que for necessária deve ser fornecida. \\
\hline & Amplitude/flexibilidade & $\begin{array}{l}\text { A informação pode ter um alcance amplo ou estreito, ou um foco } \\
\text { interno ou externo. }\end{array}$ \\
\hline & Desempenho & $\begin{array}{l}\text { A informação pode revelar desempenho pela mensuração das } \\
\text { atividades concluídas, do progresso realizado ou dos recursos } \\
\text { acumulados. }\end{array}$ \\
\hline & Simplicidade & A informação deve ser simples, não excessivamente complexa. \\
\hline & Verificabilidade & $\begin{array}{l}\text { A informação pode ser verificada e sua correção pode ser } \\
\text { assegurada. }\end{array}$ \\
\hline & Confiabilidade & $\begin{array}{l}\text { A informação depende de algum outro fator como o método de } \\
\text { coleta de dados e a fonte da informação. O usuário precisa } \\
\text { acreditar na informação para se sentir seguro ao decidir. }\end{array}$ \\
\hline & Comparação & $\begin{array}{l}\text { Refletem a comparação dos planos com a execução (planejado x } \\
\text { real) e tendências, como por exemplo, comparações com períodos } \\
\text { anteriores (mês, ano etc.). }\end{array}$ \\
\hline \multirow{5}{*}{ Forma } & Clareza/interpretabilidade & $\begin{array}{l}\text { A informação deve ser fornecida de uma forma que seja fácil de } \\
\text { compreender. }\end{array}$ \\
\hline & Detalhe & $\begin{array}{l}\text { A informação pode ser fornecida em forma detalhada ou resumida. } \\
\text { As informações devem aparecer num nível de síntese adequada ao } \\
\text { nível do usuário, sem apresentar nada de irrelevante para o usuário } \\
\text { e tampouco num grau de síntese excessivo com relação ao seu } \\
\text { interesse. }\end{array}$ \\
\hline & Ordem & $\begin{array}{l}\text { A informação pode ser organizada em uma seqüência } \\
\text { predeterminada. }\end{array}$ \\
\hline & Apresentação & $\begin{array}{l}\text { A informação pode ser apresentada em forma narrativa, numérica, } \\
\text { gráfica ou outras. }\end{array}$ \\
\hline & Mídia & $\begin{array}{l}\text { A informação pode ser fornecida na forma de documentos em papel } \\
\text { impresso, monitores de vídeo ou outras mídias. }\end{array}$ \\
\hline
\end{tabular}

Fonte: Adaptado de Bio (1996), Stair \& Reynolds (2011) e O'Brien (2004)

\section{O INSTRUMENTO DE AVALIAÇÃO DA QUALIDADE DA INFORMAÇÃO}

É apresentado o instrumento de avaliação da QI, com base nos atributos de QI e nos moldes do instrumento SERVQUAL (PARASURAMAN et al., 1985; PARASURAMAN et al., 1988). Segundo Freitas et al. (2006), os itens de avaliação do instrumento SERVQUAL devem ser adaptados à natureza do objeto a ser Revista Produção Online, Florianópolis, SC, v.12, n. 4, p. 1084-1105, out./dez. 2012. 
avaliado. Sendo assim, para o presente instrumento, os autores consideraram as dimensões de QI, uma vez que o foco passa a ser a informação.

O presente instrumento é ilustrado pelo Quadro 3, que foi adaptado de Bio (1996), Stair \& Reynolds (2011) e O'Brien (2004) - quanto aos atributos de qualidade, e Salomi et al. (2005) - quanto à estrutura do instrumento.

Quadro 3 - Dimensões e atributos de QI esperados e percebidos

\begin{tabular}{|c|c|c|}
\hline & Expectativas (E) & Percepções (P) \\
\hline \multirow{5}{*}{ 总 } & $\begin{array}{l}\text { Prontidão - a informação deveria ser fornecida quando } \\
\text { necessária. }\end{array}$ & $\begin{array}{l}\text { Prontidão - a informação é fornecida quando } \\
\text { necessária. }\end{array}$ \\
\hline & $\begin{array}{l}\text { Pontualidade - a informação deveria estar próxima do } \\
\text { fato. }\end{array}$ & Pontualidade - a informação está próxima do fato. \\
\hline & $\begin{array}{c}\text { Atualização - a informação deveria estar atualizada } \\
\text { quando fornecida. }\end{array}$ & $\begin{array}{l}\text { Atualização - a informação está atualizada quando } \\
\text { fornecida. }\end{array}$ \\
\hline & $\begin{array}{c}\text { Freqüência - a informação deveria ser fornecida tantas } \\
\text { vezes quantas são necessárias. }\end{array}$ & $\begin{array}{c}\text { Freqüência - a informação é fornecida tantas vezes } \\
\text { quantas são necessárias. }\end{array}$ \\
\hline & $\begin{array}{l}\text { Período - a informação de } \\
\text { períodos passados, } p\end{array}$ & $\begin{array}{c}\text { Período - a informação é fornecida sobre } \mathrm{p} \\
\text { passados, presentes e futuros. }\end{array}$ \\
\hline \multirow{11}{*}{ 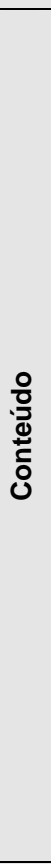 } & $\begin{array}{l}\text { Precisão/correção - a informação deveria estar isenta de } \\
\text { erros. }\end{array}$ & $\begin{array}{l}\text { Precisão/correção - a informação está isenta de } \\
\text { erros. }\end{array}$ \\
\hline & $\begin{array}{l}\text { Relevância/exceção - a informação deveria estar } \\
\text { relacionada às necessidades de informação de um receptor } \\
\text { específico para uma situação específica; deveria ser } \\
\text { destacado o que é relevante, as exceções. }\end{array}$ & $\begin{array}{l}\text { Relevância/exceção - a informação está relacionada } \\
\text { às necessidades de informação de um receptor } \\
\text { específico para uma situação específica; é destacado o } \\
\text { que é relevante, as exceções. }\end{array}$ \\
\hline & $\begin{array}{l}\text { Integridade - toda informação necessária deveria ser } \\
\text { fornecida. }\end{array}$ & Integridade - toda informação necessária é fornecida. \\
\hline & $\begin{array}{r}\text { Completude - a informação } \\
\text { todos os fatos in }\end{array}$ & $\begin{array}{r}\text { Completude - a informaçãc } \\
\text { fatos imp }\end{array}$ \\
\hline & $\begin{array}{r}\text { Concisão - apenas a infor } \\
\text { forr }\end{array}$ & $\begin{array}{r}\text { Concisão - apenas a } \\
\text { forn }\end{array}$ \\
\hline & $\begin{array}{l}\text { Amplitude/flexibilidade - a informação c } \\
\text { alcance amplo ou estreito, ou um foco inte }\end{array}$ & $\begin{array}{r}\text { Amplitude/flexibilidade - } \\
\text { alcance amplo ou estreito, } \\
\text { extern }\end{array}$ \\
\hline & $\begin{array}{r}\text { Desempenho - a informaç } \\
\text { pela mensuração das ativi } \\
\text { realizado ou dos }\end{array}$ & $\begin{array}{l}\text { Desempenho - a informação } \\
\text { mensuração das atividades } \\
\text { realizado ou dos recu }\end{array}$ \\
\hline & $\begin{array}{r}\text { Simplicidade }- \text { a informa } \\
\text { excessivam }\end{array}$ & $\begin{array}{r}\text { Simplicidade - a inf } \\
\text { excessivame }\end{array}$ \\
\hline & $\begin{array}{r}\text { Verificabilidade - deveria s } \\
\text { informação e assegura }\end{array}$ & $\begin{array}{c}\text { Verificabilidade - é possível verificar a informação e } \\
\text { assegurar sua correção. }\end{array}$ \\
\hline & $\begin{array}{l}\text { Confiabilidade }- \text { a inform } \\
\text { poder ser utilizada sem risc }\end{array}$ & $\begin{array}{l}\text { Confiabilidade - a informação é confiável e pode ser } \\
\text { utilizada sem risco para a tomada de decisão. }\end{array}$ \\
\hline & $\begin{array}{l}\text { Comparação - a informação deveria refletir a comparação } \\
\text { do planejado com o realizado, assim como, tendências. }\end{array}$ & $\begin{array}{l}\text { Comparação - a informação reflete a comparação do } \\
\text { planejado com o realizado, assim como, tendências. }\end{array}$ \\
\hline \multirow{5}{*}{ हृ } & $\begin{array}{l}\text { Clareza - a informação deveria ser fornecida de uma } \\
\text { forma que fosse fácil de compreender. }\end{array}$ & $\begin{array}{c}\text { Clareza - a informação é fornecida de uma forma que } \\
\text { seja fácil de compreender. }\end{array}$ \\
\hline & $\begin{array}{c}\text { Detalhe - as informações deveriam aparecer num nível de } \\
\text { síntese adequada ao nível do usuário, sem apresentar } \\
\text { nada de irrelevante e tampouco num grau de síntese } \\
\text { excessivo com relação ao seu interesse. }\end{array}$ & $\begin{array}{c}\text { Detalhe - as informações aparecem num nível de } \\
\text { síntese adequada ao nível do usuário, sem apresentar } \\
\text { nada de irrelevante e tampouco num grau de síntese } \\
\text { excessivo com relação ao seu interesse. }\end{array}$ \\
\hline & $\begin{array}{l}\text { Ordem - a informação deveria ser apresentada } \\
\text { organizada numa seqüência predeterminada. }\end{array}$ & $\begin{array}{c}\text { Ordem - a informação é apresentada organizada numa } \\
\text { seqüência predeterminada. }\end{array}$ \\
\hline & $\begin{array}{l}\text { Apresentação - a informação deveria ser apresentada em } \\
\text { forma narrativa, numérica, gráfica ou outras. }\end{array}$ & $\begin{array}{c}\text { Apresentação - a informação é apresentada em forma } \\
\text { narrativa, numérica, gráfica ou outras. }\end{array}$ \\
\hline & $\begin{array}{l}\text { Mídia - a informação deveria ser fornecida na forma de } \\
\text { documentos em papel impresso, monitores de vídeo ou } \\
\text { outras mídias. }\end{array}$ & $\begin{array}{c}\text { Mídia - a informação é fornecida na forma de } \\
\text { documentos em papel impresso, monitores de vídeo ou } \\
\text { outras mídias. }\end{array}$ \\
\hline
\end{tabular}

Discordo fortemente

Concordo fortemente

Fonte: Adaptado de Bio (1996), Stair \& Reynolds (2011), O’Brien (2004) e Salomi et al. (2005). 
Os itens de avaliação do instrumento SERVQUAL original deram lugar aos atributos de QI. Ainda assim, não se pretende com isso, "engessar" o instrumento, mas possibilitar que qualquer atributo de QI seja avaliado.

Baseado em Parasuraman et al. (1985), o instrumento de avaliação foi aplicado em dois momentos: no levantamento da qualidade esperada (E) da informação - com base nos requisitos do usuário - e no levantamento da qualidade percebida $(P)$ da informação - com base no uso da informação.

Segundo Parasuraman et al. (1985), a qualidade (Q) resulta da diferença entre a percepção $(P)$ e a expectativa $(E)$, ou seja, $(Q=P-E)$. Assim, se o gap resultante for negativo, então o nível de qualidade está aquém do que se esperava, resultando em uma qualidade inaceitável.

Estes indicadores podem auxiliar na identificação de gaps existentes entre as expectativas e percepções de usuários e gestores da informação. Assim, com base no Modelo Gap (PARASURAMAN et al., 1985), os autores adaptaram a definição desses gaps sob a perspectiva da QI:

- Gap 1: discrepância entre as expectativas dos usuários da informação e as percepções dos gestores da informação sobre essas expectativas;

- Gap 2: discrepância entre a percepção dos gestores da informação em relação às expectativas dos usuários da informação e a especificação da informação;

- Gap 3: discrepância entre a especificação da informação e as informações realmente oferecidas;

- Gap 4: discrepância entre as informações oferecidas e o que é comunicado ao usuário;

- Gap 5: discrepância entre o que o usuário da informação espera receber e a percepção que ele tem das informações oferecidas.

Então, esse modelo de gaps foi adequado para a QI evidenciando que a expectativa dos usuários pode ser uma confluência de necessidades de informações:

i. para medições de desempenho (ad hoc ou não; referências cruzadas e indicadores);

ii. para avaliação de cenários de decisão (simulações), e;

iii. para consultas em dados históricos (relatórios e gráficos).

Revista Produção Online, Florianópolis, SC, v.12, n. 4, p. 1084-1105, out./dez. 2012. 
Assim, baseado em Jiang et al. (2003), são apresentadas questões de gerenciamento com a finalidade de identificar gaps existentes na avaliação da Ql.

O gap de expectativa: Quais são as expectativas dos clientes sobre as informações fornecidas? Quais são as expectativas dos gestores da informação? Os gestores da informação entendem as expectativas de seus usuários? Se não, onde estão os gaps? Esta medida de gap de expectativa inclui expectativas atuais dos clientes, percepção dos gerentes sobre estas expectativas, e a habilidade dos gerentes em atender baseados em padrões de QI.

O gap de percepção: Quais são as percepções dos clientes sobre a informação entregue? Quais são as percepções dos gestores da informação sobre o desempenho da informação? Eles aceitam? Se não, os clientes estão muito ou pouco satisfeitos com o desempenho da informação? O gap de desempenho representa uma inabilidade para atender às expectativas.

A informação e o usuário da QI: Quais são as percepções dos usuários sobre a QI? Eles estão satisfeitos com as informações fornecidas? Se não, quais informações precisam ser melhoradas? Quais são as percepções dos gestores da informação sobre a qualidade das informações? Eles estão satisfeitos com seu desempenho? Se não, quais informações precisam ser melhoradas? Estas medidas representam o gap (G) entre as perspectivas dos usuários e dos gestores da informação.

O gap de satisfação: Há um gap na QI medida entre os usuários e os gestores de informações? Se sim, quais dimensões e atributos contribuem para este gap? Estes são independentes para os dois grupos (usuários e gerentes) e as expectativas e percepções de cada grupo são unicamente identificadas.

Assim como Jiang et al. (2003), acredita-se que as respostas a estas questões possibilitem um diagnóstico rico sobre a QI fornecida e forneçam uma medida para promover um melhor gerenciamento da QI. Grandes gaps indicam que gestores da informação não entenderam os requisitos de seus usuários; um mau entendimento pode fazer com que informações de má qualidade sejam oferecidas aos usuários, resultando em insatisfação e afetando seriamente o processo decisório. 


\section{MÉTODO DE PESQUISA}

No aspecto teórico, na busca de referências bibliográficas e na busca de soluções existentes para o problema proposto, este trabalho pode ser classificado como uma pesquisa bibliográfica (GIL, 1987; CERVO \& BERVIAN, 2002).

Quanto aos aspectos práticos e empíricos, a pesquisa poderia ser classificada, segundo Miguel (2007), como experimental de campo, uma vez que existem condições que não são controladas pelo pesquisador.

Miguel (2007) afirma que as pesquisas bibliográficas e experimentais são mais comuns em engenharia de produção, dentre outras, como teórico-conceituais, estudo de caso, surveys, modelamento e simulação, e pesquisa-ação. Aliás, é importante frisar que este estudo não se classifica como pesquisa-ação, pois não houve envolvimento e nem intervenção dos pesquisadores e demais participantes representativos dos cenários pesquisados de modo cooperativo e participativo (GIL, 1987; KRAFTA et al., 2009).

Definido o método de pesquisa, os dados, então, foram coletados a partir da aplicação do instrumento proposto, por meio do qual, buscou-se avaliar as informações da organização pesquisada a fim de aferir a efetividade do instrumento.

A empresa que participou desta pesquisa foi escolhida por apresentar um cenário favorável, no qual foi possível aferir a efetividade de pacotes de dados e informações técnicas relacionados à área de engenharia da empresa e seus terceirizados. Neste caso, havia a possibilidade do instrumento proposto ser adotado definitivamente pela empresa, segundo seus gestores.

A análise dos dados foi feita a partir do tratamento dos dados coletados da pesquisa experimental pelo instrumento de avaliação da QI, que compreendem os graus atribuídos à expectativa, à percepção e os gaps de satisfação derivados da diferença entre a expectativa e a percepção dos usuários da informação.

Da análise derivaram-se dados estatísticos dos graus atribuídos e, a partir de seu resultado, sugeriu-se a classificação de prioridades dos atributos de QI por meio do cálculo de quartis, além da análise de consistência do instrumento de avaliação.

No caso do cálculo de quartis, o objetivo foi apontar atributos de qualidade que apresentassem gaps de insatisfação e, conseqüentemente, representassem um problema para a organização. A partir dessa análise, foi proposto pelos 
pesquisadores que esses problemas fossem sanados por meio de método de solução de problemas, por exemplo.

A análise de consistência da escala do instrumento se deu por meio do coeficiente de correlação alfa de Cronbach (1951), além do coeficiente de variação.

\section{A PESQUISA DE CAMPO}

A pesquisa experimental de campo foi realizada em uma empresa multinacional do setor metal-mecânico, localizada em São Paulo-SP, no período de 28 de agosto de 2009 a 19 de fevereiro de 2010. Esta empresa, neste estudo, será cognominada e referenciada daqui em diante como empresa "A".

\subsection{Cenário da pesquisa}

Após analisar, juntamente com um dos gestores da empresa "A", os possíveis cenários nos quais o instrumento poderia ser aplicado, foi disponibilizado o setor de engenharia e projetos. Este setor é responsável por analisar (levantar necessidades e medidas) e projetar as estruturas metálicas envolvidas nos projetos contratados por seus clientes. Este setor, segundo fonte interna da empresa "A", conta com aproximadamente cem funcionários, envolvendo engenheiros, projetistas e estagiários.

No entanto, o gestor do setor em questão constatou que este não era favorável ao estudo, uma vez que os dados coletados poderiam se apresentar tendenciosos. A razão disso era o fato de que os funcionários envolvidos no estudo, por terem muito tempo de empresa e já conhecerem as informações das quais fazem uso, poderiam fornecer uma avaliação tendenciosa, comprometendo a fidedignidade dos resultados. Assim, o gestor do setor de engenharia sugeriu envolver no estudo uma das empresas terceirizadas de engenharia, que será neste estudo, cognominada e referenciada daqui em diante como empresa " $A_{1}$ ".

A relação entre essas duas empresas é descrita a seguir e ilustrada pela Figura 1:

(1) quando o volume de serviço é grande, a empresa " $A$ " contrata os serviços de engenharia e projeto da empresa " $A_{1}$ ";

Revista Produção Online, Florianópolis, SC, v.12, n. 4, p. 1084-1105, out./dez. 2012. 
(2) a empresa "A" envia à empresa " $\mathrm{A}_{1}$ " todos os dados e informações necessários ao desenvolvimento dos projetos, assim como os prazos de entrega dos serviços;

(3) com base nas informações passadas pela empresa "A", a empresa " $A_{1}$ " desenvolve, então, os projetos solicitados;

(4) eventualmente, a empresa " $A_{1}$ " contata a empresa "A" para sanar dúvidas quanto aos dados ou informações transmitidas, ou ao projeto em si;

(5) finalmente, os projetos são entregues à empresa " $A$ " pela empresa " $A_{1}$ ".

Figura 1 - Relação entre as empresas "A" e " $A_{1}$ "

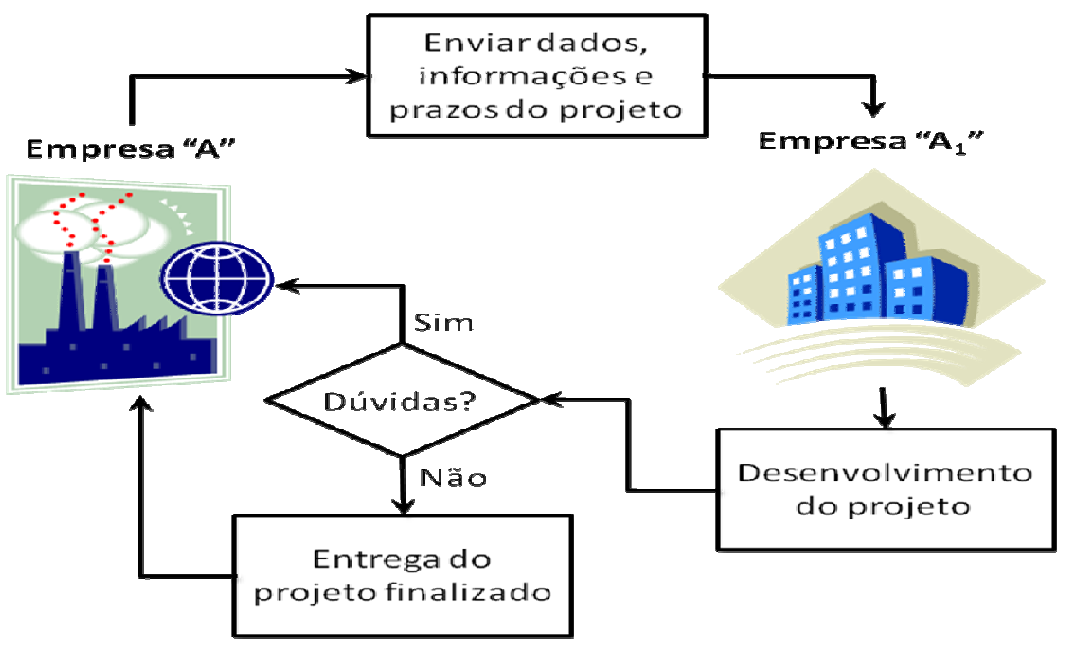

Este novo cenário sugerido pela empresa "A" tem seu esquema de aplicação do instrumento de avaliação da QI ilustrado pela Figura 2 e se apresentava favorável pelas seguintes razões:

- o setor de engenharia da empresa "A" se apresentava como fonte geradora de dados e informações;

- a empresa " $\mathrm{A}_{1}$ " se apresentava como usuária destas informações;

- o gestor da empresa " $A_{1}$ ", em entrevista, sinalizou que existem problemas relacionados à qualidade das informações que recebe da empresa "A", o que ocasiona problemas no desenvolvimento do projeto e resulta num serviço de má qualidade, além de atraso na entrega dos projetos; 
- o instrumento de avaliação da QI, neste cenário, poderia contribuir apontando problemas na geração e fornecimento de informações à empresa " $\mathrm{A}_{1}$ ".

Figura 2 - Esquema de aplicação do instrumento de avaliação da QI entre as empresas "A" e "A ${ }_{1}$ "

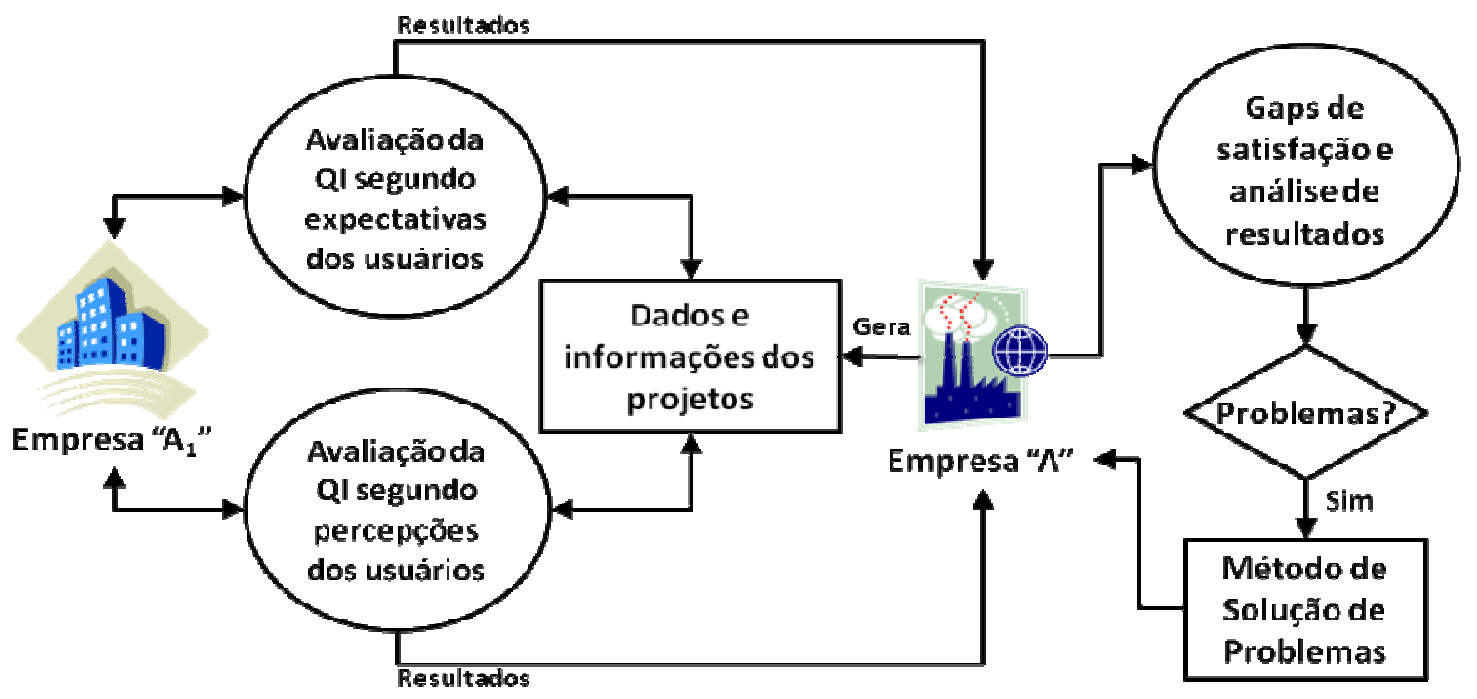

\subsection{Resultado da pesquisa experimental}

Antes de serem apresentados os resultados cabe ressaltar que os atributos de qualidade pontualidade, freqüência, período, concisão, desempenho, simplicidade e comparação não foram avaliados, pelo fato de não agregarem valor à informação, segundo o avaliador.

Foram avaliados 14 conjuntos de dados e informações técnicas diferentes, relacionadas ao mesmo projeto de engenharia (cognominado neste estudo como "Projeto X"), por um único avaliador - o engenheiro da empresa " $A_{1}$ ". Sem tê-los em mãos, mas tendo conhecimento dos dados que seriam enviados pela empresa "A", o engenheiro da empresa " $A_{1}$ " quantificou os atributos de qualidade de cada um dos conjuntos, segundo suas expectativas. Entre a segunda quinzena de dezembro de 2009 e a primeira quinzena de janeiro de 2010, a empresa " $A$ " enviou à empresa " $A_{1}$ " os dados técnicos do referido projeto de engenharia ("Projeto X"), que foram avaliados segundo as percepções do engenheiro da empresa " $A_{1}$ ".

Revista Produção Online, Florianópolis, SC, v.12, n. 4, p. 1084-1105, out./dez. 2012. 
Com relação às expectativas, os resultados, ilustrados pela Figura 3, demonstram que o grau de expectativa do avaliador era alto no momento da avaliação das informações.

A Tabela 1 apresenta os graus atribuídos, de acordo com as expectativas do avaliador, as respectivas médias aritméticas, coeficientes de variação $\left(C_{v}\right)$ e coeficientes de correlação alfa de Cronbach $(\alpha)$. Observa-se que o coeficiente de variação $\left(C_{v}\right)$ foi pouco significativo. Ainda, ao desconsiderar cada um dos itens do instrumento (atributos de qualidade), o alfa de Cronbach pouco se alterou com relação ao alfa total $(0,857)$. Com esse resultado, foi possível verificar níveis aceitáveis de confiabilidade dos múltiplos itens do instrumento para as expectativas, apesar de ter-se descartado sete atributos de qualidade.

Figura 3 - Percentual dos graus atribuídos na avaliação da QI pela Empresa " $A_{1}$ ", segundo as expectativas do avaliador

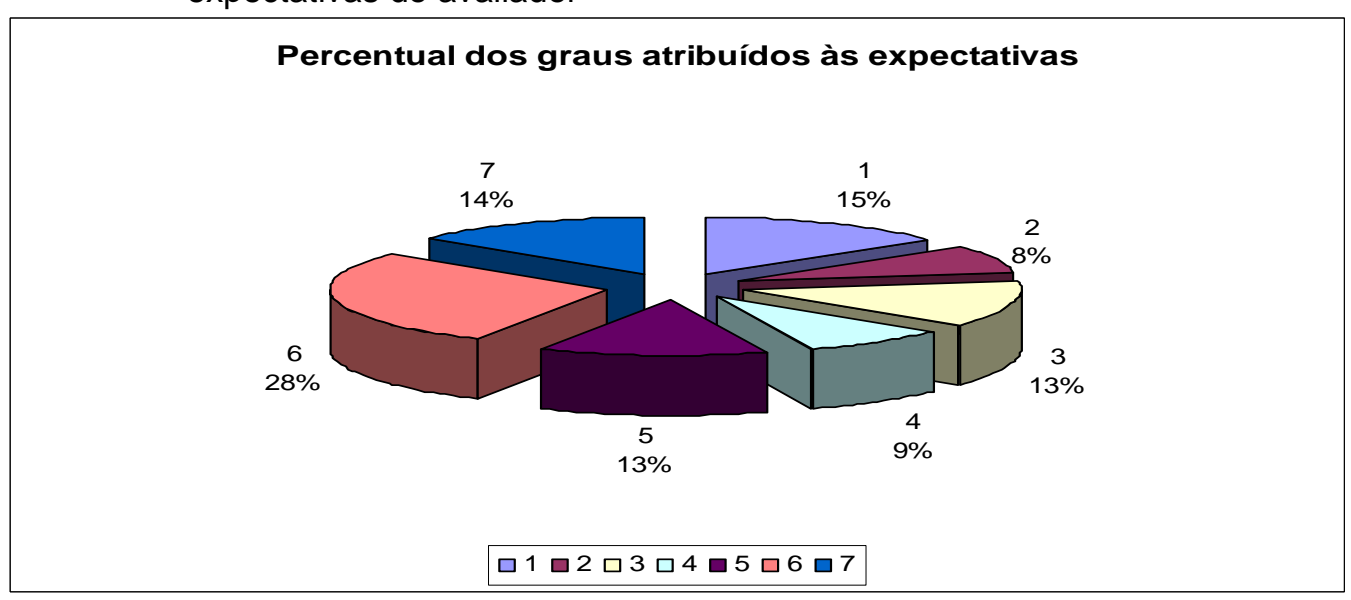

Observa-se que, apesar dos dados e informações técnicas serem diferentes, as expectativas não variam muito. Isso ocorre, segundo o avaliador, porque suas expectativas não se alteram, independente do projeto.

Durante a avaliação da QI segundo as expectativas, o engenheiro da empresa " $\mathrm{A}_{1}$ " sentiu dificuldade em compreender o significado de alguns atributos de qualidade. Além disso, a escala de 7 pontos também causou certa confusão na atribuição de graus. Sobre isso, é importante frisar que, antes de dar continuidade à avaliação da QI segundo as percepções do avaliador, os pesquisadores realizaram alguns ajustes nas definições dos atributos. 
Tabela 1 - Avaliação da QI pela Empresa " $\mathrm{A}_{1}$ ", segundo as expectativas do avaliador Avaliação da Qualidade da Informação "Projeto X"

\begin{tabular}{|c|c|c|c|c|c|c|c|c|c|c|c|c|c|c|c|c|c|c|}
\hline \multirow{2}{*}{ 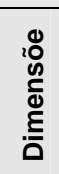 } & \multirow[b]{2}{*}{$\begin{array}{l}\text { Atributos de } \\
\text { Qualidade }\end{array}$} & \multicolumn{17}{|c|}{ Expectativas } \\
\hline & & 11 & 12 & 13 & 14 & 15 & 16 & 17 & 18 & 19 & 110 & I11 & 112 & 113 & 114 & & $C_{v}$ & $a$ \\
\hline \multirow{2}{*}{ 吕 } & Prontidão & 7 & 7 & 7 & 7 & 7 & 7 & 7 & 7 & 7 & 7 & 7 & 7 & 7 & 7 & 7,00 & 0,00 & 0,884 \\
\hline & Atualização & 6 & 6 & 6 & 6 & 6 & 6 & 6 & 6 & 6 & 6 & 6 & 6 & 6 & 6 & 6,00 & 0,00 & 0,884 \\
\hline \multirow{7}{*}{$\begin{array}{l}\frac{0}{0} \\
\frac{0}{0} \\
\frac{0}{2} \\
0\end{array}$} & $\begin{array}{l}\text { Precisão/ } \\
\text { correção }\end{array}$ & 7 & 7 & 7 & 7 & 7 & 7 & 7 & 7 & 7 & 7 & 7 & 7 & 7 & 7 & 7,00 & 0,00 & 0,884 \\
\hline & $\begin{array}{l}\text { Relevância/ } \\
\text { exceção }\end{array}$ & 6 & 6 & 4 & 6 & 6 & 6 & 6 & 6 & 6 & 6 & 6 & 6 & 6 & 6 & 5,86 & 0,09 & 0,867 \\
\hline & Integridade & 6 & 6 & 6 & 6 & 6 & 6 & 6 & 6 & 6 & 6 & 6 & 6 & 6 & 6 & 6,00 & 0,00 & 0,884 \\
\hline & Completude & 5 & 5 & 4 & 5 & 5 & 5 & 5 & 5 & 5 & 5 & 5 & 5 & 5 & 5 & 4,93 & 0,05 & 0,843 \\
\hline & $\begin{array}{l}\text { Amplitude/ } \\
\text { flexibilidade }\end{array}$ & 5 & 5 & 4 & 5 & 5 & 5 & 5 & 5 & 5 & 5 & 5 & 5 & 5 & 5 & 4,93 & 0,05 & 0,843 \\
\hline & Verificabilidade & 4 & 4 & 4 & 4 & 4 & 4 & 4 & 4 & 4 & 4 & 4 & 4 & 4 & 4 & 4,00 & 0,00 & 0,884 \\
\hline & Confiabilidade & 6 & 6 & 6 & 6 & 6 & 6 & 6 & 6 & 6 & 6 & 6 & 6 & 6 & 6 & 6,00 & 0,00 & 0,884 \\
\hline \multirow{5}{*}{$\begin{array}{l}\stackrel{0}{\xi} \\
\text { 훈 }\end{array}$} & Clareza & 3 & 3 & 2 & 3 & 3 & 3 & 3 & 3 & 3 & 3 & 3 & 3 & 3 & 3 & 2,93 & 0,09 & 0,843 \\
\hline & Detalhe & 3 & 3 & 2 & 3 & 3 & 3 & 3 & 3 & 3 & 3 & 3 & 3 & 3 & 3 & 2,93 & 0,09 & 0,843 \\
\hline & Ordem & 2 & 2 & 1 & 2 & 2 & 2 & 2 & 2 & 2 & 2 & 2 & 2 & 2 & 2 & 1,93 & 0,14 & 0,843 \\
\hline & Apresentação & 1 & 1 & 1 & 1 & 1 & 1 & 1 & 1 & 1 & 1 & 1 & 1 & 1 & 1 & 1,00 & 0,00 & 0,884 \\
\hline & Mídia & 1 & 1 & 1 & 1 & 1 & 1 & 1 & 1 & 1 & 1 & 1 & 1 & 1 & 1 & 1,00 & 0,00 & 0,884 \\
\hline
\end{tabular}

Com relação às percepções, a avaliação das informações segundo as percepções confirmou a afirmação do engenheiro da empresa " $A_{1}$ " de que, por vezes, as informações enviadas pela empresa "A" são de má qualidade.

Figura 4 - Percentual dos graus atribuídos na avaliação da Ql pela Empresa " $A_{1}$ ", segundo as percepções do avaliador

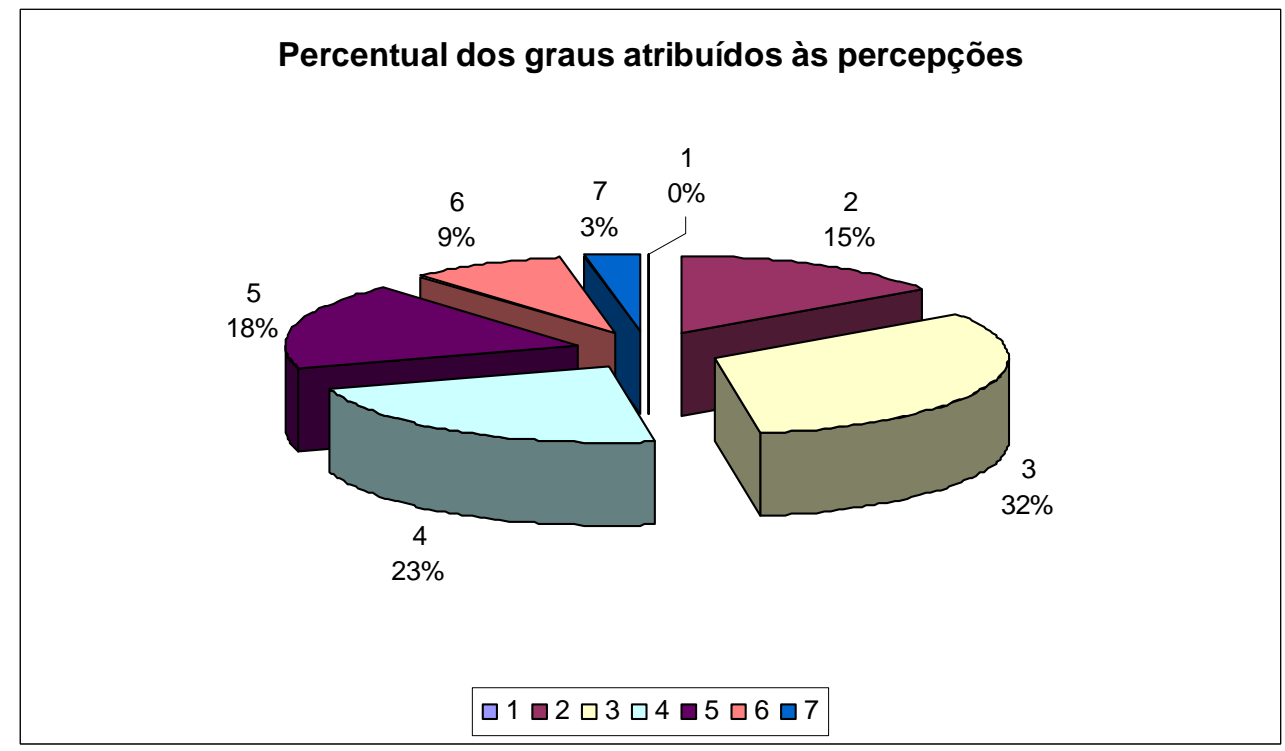

A Tabela 2 apresenta os graus atribuídos, segundo as percepções do avaliador, a cada um dos atributos de qualidade avaliados, suas respectivas médias Revista Produção Online, Florianópolis, SC, v.12, n. 4, p. 1084-1105, out./dez. 2012. 
aritméticas, coeficiente de variação $\left(C_{v}\right)$ e coeficiente de correlação alfa de Cronbach $(\alpha)$. Apesar do coeficiente de variação $\left(C_{V}\right)$ apresentar-se acima de 0,30 para metade dos atributos de qualidade avaliados (Prontidão, Atualização, Integridade, Completude, Amplitude/Flexibilidade, Verificabilidade e Confiabilidade), o alfa de Cronbach, desconsiderando cada um dos atributos, praticamente não sofreu alterações em relação ao alfa total $(0,980)$. Com isso, foi possível verificar que os níveis de confiabilidade dos múltiplos itens (atributos de qualidade) do instrumento de avaliação são aceitáveis, para as percepções.

Tabela 2 - Avaliação da QI pela Empresa "A,", segundo as percepções do avaliador

$$
\text { Avaliação da Qualidade da Informação "Projeto X" }
$$

\begin{tabular}{|c|c|c|c|c|c|c|c|c|c|c|c|c|c|c|c|c|c|c|}
\hline \multicolumn{19}{|c|}{ Avaliação da Qualidade da Informação "Projeto X" } \\
\hline \multirow[b]{2}{*}{ 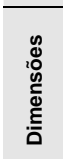 } & \multirow[b]{2}{*}{$\begin{array}{l}\text { Atributos de } \\
\text { Qualidade }\end{array}$} & \multicolumn{17}{|c|}{ 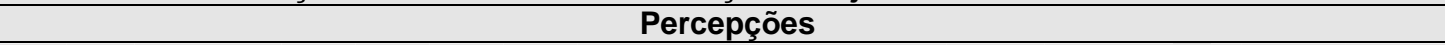 } \\
\hline & & 11 & 12 & 13 & 14 & 15 & 16 & 17 & 18 & 19 & 110 & I11 & I12 & 113 & 114 & 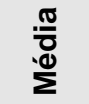 & $C_{v}$ & $\alpha$ \\
\hline \multirow[t]{2}{*}{ 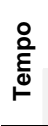 } & Prontidão & 3 & 3 & 2 & 4 & 4 & 3 & 3 & 3 & 2 & 7 & 4 & 7 & 7 & 7 & 4,21 & 0,46 & 0,978 \\
\hline & Atualização & 3 & 3 & 2 & 4 & 4 & 3 & 3 & 3 & 2 & 6 & 4 & 6 & 4 & 5 & 3,71 & 0,34 & 0,978 \\
\hline \multirow{7}{*}{ 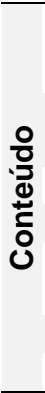 } & $\begin{array}{l}\text { Precisão/ } \\
\text { correção }\end{array}$ & 4 & 4 & 3 & 4 & 5 & 4 & 4 & 4 & 3 & 7 & 5 & 7 & 4 & 6 & 4,57 & 0,28 & 0,979 \\
\hline & $\begin{array}{l}\text { Relevância/ } \\
\text { exceção }\end{array}$ & 4 & 4 & 3 & 5 & 5 & 4 & 4 & 4 & 3 & 6 & 5 & 6 & 6 & 6 & 4,64 & 0,23 & 0,978 \\
\hline & Integridade & 2 & 2 & 2 & 3 & 3 & 2 & 2 & 3 & 2 & 6 & 3 & 6 & 5 & 6 & 3,36 & 0,49 & 0,977 \\
\hline & Completude & 2 & 2 & 2 & 3 & 3 & 2 & 2 & 3 & 2 & 6 & 3 & 6 & 5 & 6 & 3,36 & 0,49 & 0,977 \\
\hline & $\begin{array}{l}\text { Amplitude/ } \\
\text { flexibilidade }\end{array}$ & 3 & 3 & 2 & 4 & 4 & 3 & 3 & 4 & 3 & 6 & 4 & 6 & 5 & 6 & 4,00 & 0,33 & 0,977 \\
\hline & Verificabilidade & 3 & 3 & 2 & 2 & 2 & 3 & 2 & 2 & 3 & 5 & 3 & 6 & 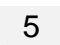 & 5 & 3,29 & 0,42 & 0,978 \\
\hline & Confiabilidac & 0 & 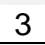 & 0 & 2 & 2 & 3 & 2 & 2 & 3 & & 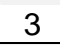 & 5 & 4 & & 00 & & 0,979 \\
\hline \multirow{5}{*}{$\begin{array}{l}\stackrel{\mathbb{\Xi}}{5} \\
\text { 문 }\end{array}$} & Clareza & 3 & 3 & 2 & 3 & 3 & 3 & 3 & 3 & 3 & 5 & 3 & 5 & 5 & 5 & 3,50 & 0,29 & 0,977 \\
\hline & Deta & 0 & 3 & 0 & 3 & ? & 0 & ? & 3 & 3 & 5 & 3 & 5 & 5 & 5 & & & 0,977 \\
\hline & Ordem & 4 & 4 & 2 & 4 & 3 & 4 & 4 & 3 & 4 & - & 4 & 5 & 5 & 5 & 4,00 & 0,22 & 0,980 \\
\hline & Apresen & 4 & 4 & 3 & . & 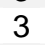 & 4 & 4 & 3 & 4 & 5 & 4 & 5 & 5 & 5 & 4 & 0,19 & 0,980 \\
\hline & Mídia & 4 & 4 & 3 & 5 & 3 & 4 & 4 & 3 & 4 & 5 & 4 & 5 & 5 & 5 & 4,14 & 0,19 & 0,980 \\
\hline
\end{tabular}

Assim, o resultado é uma quantidade considerável de gaps negativos, conforme pode ser observado na Figura 5. 
Figura 5 - Média dos gaps resultantes da avaliação da QI pela Empresa " $\mathrm{A}_{1}$ "

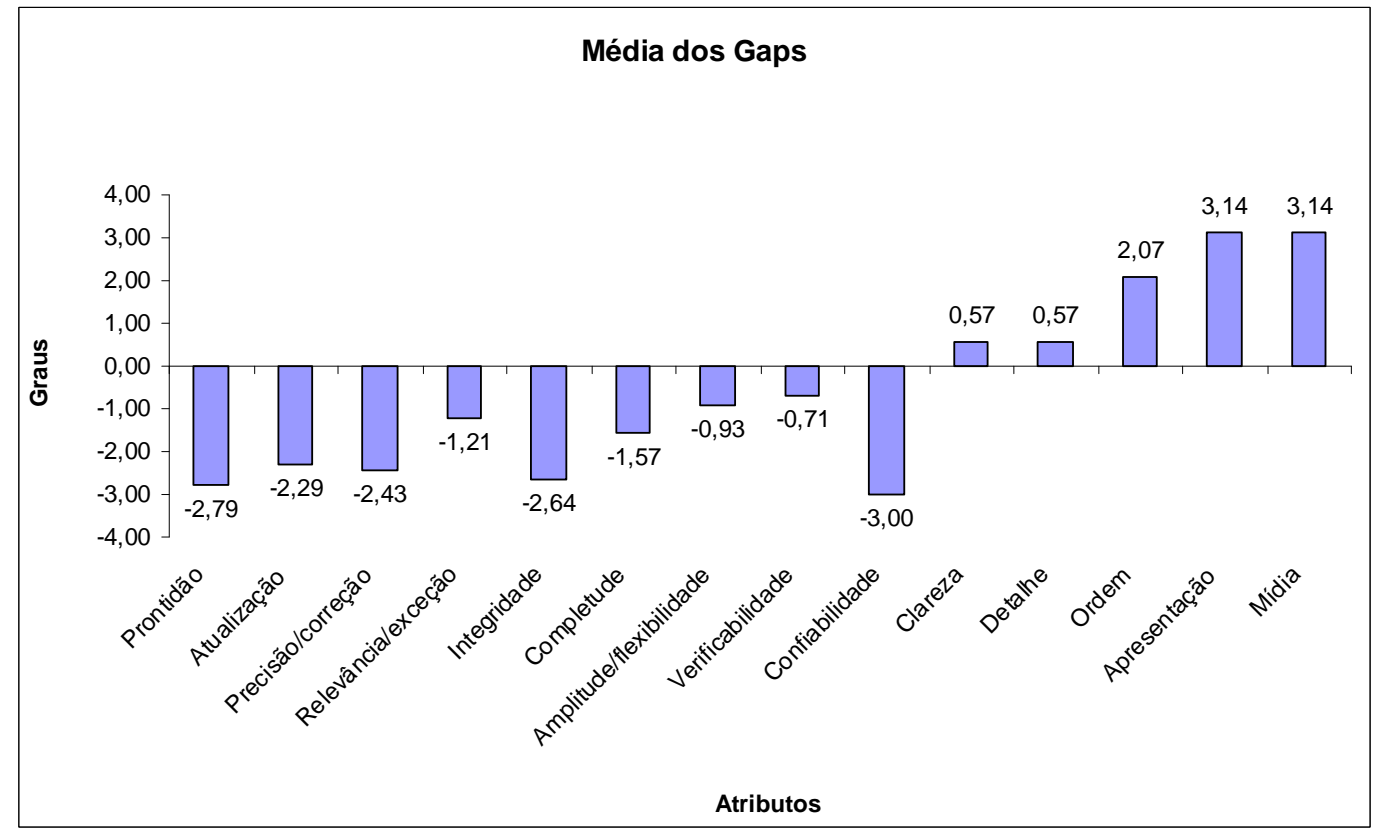

Observa-se, por meio da Tabela 3, que a maioria dos atributos de qualidade das dimensões tempo e conteúdo estava muito aquém do esperado. Até mesmo as informações $\mathbf{I 1 0}$ e $\mathbf{I 1 2}$ resultaram insatisfatórias, pois tiveram um único gap negativo no atributo confiabilidade. É importante enfatizar, porém, que os gaps apurados estão ligados ao avaliador, ou seja, às suas expectativas e percepções pessoais.

Tabela 3 - Gaps resultantes da avaliação da QI pela Empresa " $A_{1}$ "

\begin{tabular}{|c|c|c|c|c|c|c|c|c|c|c|c|c|c|c|c|c|}
\hline \multicolumn{17}{|c|}{ Avaliação da Qualidade da Informação "Projeto X" } \\
\hline \multirow[b]{2}{*}{ 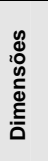 } & \multirow[b]{2}{*}{$\begin{array}{l}\text { Atributos de } \\
\text { Qualidade }\end{array}$} & \multicolumn{15}{|c|}{ Gaps de Satisfação } \\
\hline & & 11 & 12 & 13 & 14 & 15 & 16 & 17 & 18 & 19 & 110 & 111 & 112 & 113 & I14 & $\frac{\pi}{\frac{\pi}{0}}$ \\
\hline \multirow{2}{*}{$\begin{array}{l}\stackrel{ }{\frac{0}{E}} \\
\text { 임 }\end{array}$} & Prontidão & -4 & -4 & -5 & -3 & -3 & -4 & -4 & -4 & -5 & 0 & -3 & 0 & 0 & 0 & $-2,79$ \\
\hline & Atualização & -3 & -3 & -4 & -2 & -2 & -3 & -3 & -3 & -4 & 0 & -2 & 0 & -2 & -1 & $-2,29$ \\
\hline \multirow{7}{*}{$\begin{array}{l}\frac{0}{0} \\
\frac{0}{0} \\
\frac{0}{2} \\
0\end{array}$} & $\begin{array}{l}\text { Precisão/ } \\
\text { correção }\end{array}$ & -3 & -3 & -4 & -3 & -2 & -3 & -3 & -3 & -4 & 0 & -2 & 0 & -3 & -1 & $-2,43$ \\
\hline & $\begin{array}{l}\text { Relevância/ } \\
\text { exceção }\end{array}$ & -2 & -2 & -1 & -1 & -1 & -2 & -2 & -2 & -3 & 0 & -1 & 0 & 0 & 0 & $-1,21$ \\
\hline & Integridade & -4 & -4 & -4 & -3 & -3 & -4 & -4 & -3 & -4 & 0 & -3 & 0 & -1 & 0 & $-2,64$ \\
\hline & Completude & -3 & -3 & -2 & -2 & -2 & -3 & -3 & -2 & -3 & 1 & -2 & 1 & 0 & 1 & $-1,57$ \\
\hline & $\begin{array}{l}\text { Amplitude/ } \\
\text { flexibilidade }\end{array}$ & -2 & -2 & -2 & -1 & -1 & -2 & -2 & -1 & -2 & 1 & -1 & 1 & 0 & 1 & $-0,93$ \\
\hline & Verificabilidade & -1 & -1 & -2 & -2 & -2 & -1 & -2 & -2 & -1 & 1 & -1 & 2 & 1 & 1 & $-0,71$ \\
\hline & Confiabilidade & -3 & -3 & -4 & -4 & -4 & -3 & -4 & -4 & -3 & -2 & -3 & -1 & -2 & -2 & $-3,00$ \\
\hline \multirow{5}{*}{ हृ } & Clareza & 0 & 0 & 0 & 0 & 0 & 0 & 0 & 0 & 0 & 2 & 0 & 2 & 2 & 2 & 0,57 \\
\hline & Detalhe & 0 & 0 & 0 & 0 & 0 & 0 & 0 & 0 & 0 & 2 & 0 & 2 & 2 & 2 & 0,57 \\
\hline & Ordem & 2 & 2 & 1 & 2 & 1 & 2 & 2 & 1 & 2 & 3 & 2 & 3 & 3 & 3 & 2,07 \\
\hline & Apresentação & 3 & 3 & 2 & 4 & 2 & 3 & 3 & 2 & 3 & 4 & 3 & 4 & 4 & 4 & 3,14 \\
\hline & Mídia & 3 & 3 & 2 & 4 & 2 & 3 & 3 & 2 & 3 & 4 & 3 & 4 & 4 & 4 & 3,14 \\
\hline
\end{tabular}

Revista Produção Online, Florianópolis, SC, v.12, n. 4, p. 1084-1105, out./dez. 2012. 


\subsection{Análise dos resultados da pesquisa}

Comparando as médias das expectativas com as médias das percepções é possível observar, por meio da Figura 6, que apenas os atributos da dimensão forma (clareza, detalhe, ordem, apresentação e mídia) superaram as expectativas do avaliador. Isso ocorreu porque, segundo o avaliador, em projetos de grandes dimensões, as expectativas sempre são as mais altas.

Figura 6 - Comparação entre as médias dos graus atribuídos às expectativas e percepções na avaliação das informações da Empresa "A"

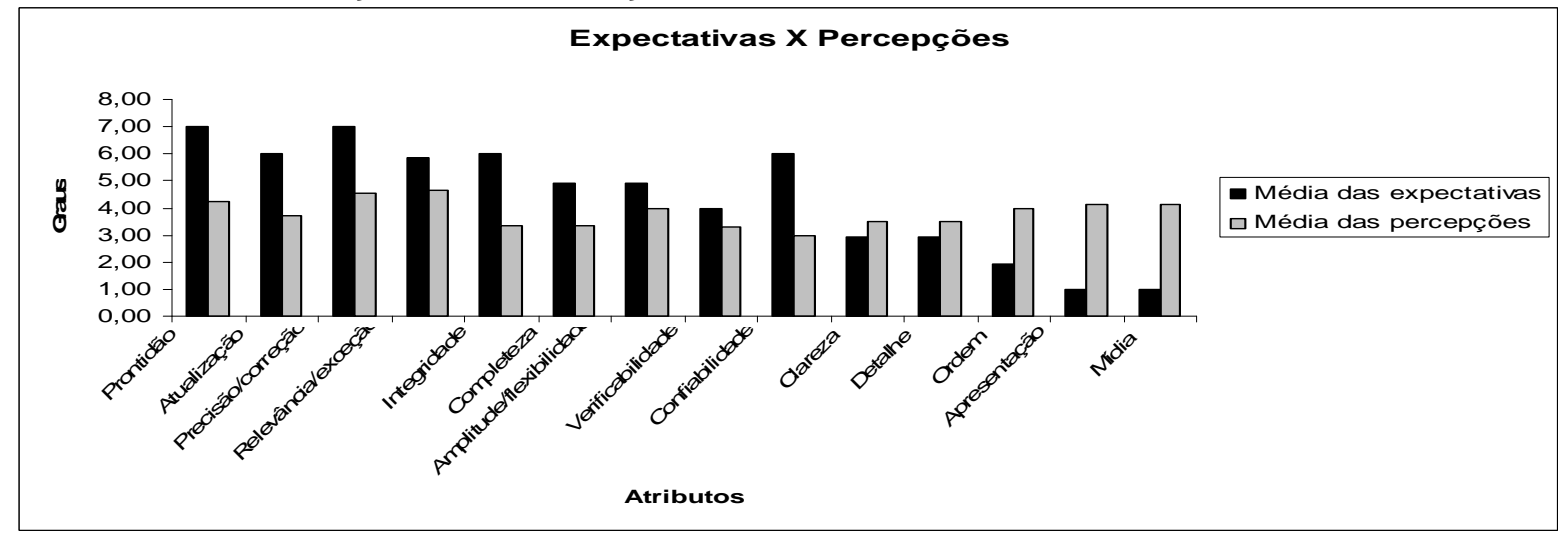

De acordo com o avaliador, essas informações técnicas de má qualidade refletem, num primeiro momento, no prazo de entrega e na qualidade do resultado final do projeto de engenharia, o que prejudica a reputação da empresa terceirizada " $A_{1}$ ". Num segundo momento, caso nenhum plano de ação seja estipulado para sanar o problema de qualidade, o impacto se dá na execução do projeto. Pode-se afirmar que este é um quadro preocupante, uma vez que estas informações técnicas são utilizadas em projetos de grande vulto.

Neste sentido, foi definida a classificação dos atributos por prioridades, apresentada pela Tabela 4, a fim de direcionar esforços na manutenção das informações técnicas transmitidas entre as empresas " $A$ " e " $A_{1}$ ".

Apesar do cálculo de quartis ter por finalidade classificar os atributos de qualidade por prioridade, a quantidade de gaps negativos é tão elevada que, na prática, a atenção se volta para todos os atributos das dimensões tempo e conteúdo. Mesmo assim, a finalidade das classificações não perde seu efeito. 
Tabela 4 - Classificação dos atributos de qualidade por prioridade, segundo gaps, percepções e expectativas, resultantes da avaliação da QI pela empresa " $A_{1}$ "

\begin{tabular}{|c|c|c|c|c|c|c|c|c|c|}
\hline \multicolumn{4}{|c|}{$\begin{array}{l}\text { CLASSIFICAÇÃO DOS ATRIBUTOS SEGUNDO OS } \\
\text { GAPS }\end{array}$} & \multicolumn{3}{|c|}{$\begin{array}{l}\text { CLASSIFICAÇÃO DOS ATRIBUTOS SEGUNDO AS } \\
\text { PERCEPÇÕES }\end{array}$} & \multicolumn{3}{|c|}{$\begin{array}{l}\text { CLASSIFICAÇÃO DOS ATRIBUTOS SEGUNDO AS } \\
\text { EXPECTATIVAS }\end{array}$} \\
\hline \multirow{15}{*}{ 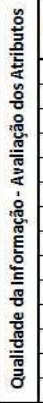 } & Prioridades & $\begin{array}{l}\text { Atributos de } \\
\text { Qualidade }\end{array}$ & $\begin{array}{c}\text { Média } \\
\text { dos Gaps }\end{array}$ & Prioridades & $\begin{array}{l}\text { Atributos de } \\
\text { Qualidade }\end{array}$ & $\begin{array}{l}\text { Média das } \\
\text { Percepções }\end{array}$ & Prioridades & $\begin{array}{l}\text { Atributos de } \\
\text { Qualidade }\end{array}$ & $\begin{array}{c}\text { Média das } \\
\text { Expectativas }\end{array}$ \\
\hline & CRÍTICA & Confiabilidade & $-3,00$ & CRÍTICA & Confiabilidade & 3,00 & CRÍTICA & Precisão/correção & 7,00 \\
\hline & CRÍTICA & Prontidão & $-2,79$ & CRÍTICA & Verificabilidade & 3,29 & CRÍTICA & Prontidão & 7,00 \\
\hline & CRÍTICA & Integridade & $-2,64$ & CRÍTICA & Completeza & 3,36 & ALTA & Aceitação & 6,00 \\
\hline & CRÍTICA & Precisão/correção & $-2,43$ & CRÍTICA & Integridade & 3,36 & ALTA & Confiabilidade & 6,00 \\
\hline & ALTA & Aceitação & $-2,29$ & ALTA & Clareza & 3,50 & ALTA & Integridade & 6,00 \\
\hline & ALTA & Completeza & $-1,57$ & ALTA & Detalhe & 3,50 & ALTA & Relevância/exceção & 5,86 \\
\hline & ALTA & Relevância/exceção & $-1,21$ & ALTA & Aceitação & 3,71 & MODERADA & Amplitude/flexibilidade & 4,93 \\
\hline & \begin{tabular}{|l|} 
MODERADA \\
\end{tabular} & Amplitude/flexibilidade & $-0,93$ & MODERADA & Amplitude/flexibilidade & 4,00 & MODERADA & Completeza & 4,93 \\
\hline & MODERADA & Verificabilidade & $-0,71$ & MODERADA & Ordem & 4,00 & MODERADA & Verificabilidade & 4,00 \\
\hline & \begin{tabular}{|l|} 
MODERADA \\
\end{tabular} & Clareza & 0,57 & MODERADA & Apresentação & 4,14 & BAIXA & Clareza & 2,93 \\
\hline & \begin{tabular}{|l|} 
MODERADA \\
\end{tabular} & Detalhe & 0,57 & MODERADA & Mídia & 4,14 & BAIXA & Detalhe & 2,93 \\
\hline & BAIXA & Ordem & 2,07 & BAIXA & Prontidão & 4,21 & BAIXA & Ordem & 1,93 \\
\hline & BAIXA & Apresentação & 3,14 & BAIXA & Precisão/correção & 4,57 & BAIXA & Apresentação & 1,00 \\
\hline & BAIXA & Mídia & 3,14 & BAIXA & Relevância/exceção & 4,64 & BAIXA & Mídia & 1,00 \\
\hline \multirow{3}{*}{\multicolumn{2}{|c|}{$\begin{array}{l}\text { Cálculo de } \\
\text { Quartis }\end{array}$}} & 1. QUARTIL & $-2,39$ & \multirow{3}{*}{$\begin{array}{l}\text { Cálculo de } \\
\text { Quartis }\end{array}$} & 19 QUARTIL & 3,3 & \multirow{3}{*}{$\begin{array}{l}\text { Cálculo de } \\
\text { Quartis }\end{array}$} & 19 QUARTIL & 2,93 \\
\hline & & 20 QUARTIL & $-1,0$ & & 20 QUARTIL & 3,8 & & 20 QUARTIL & \\
\hline & & 30 QUARTIL & 0,57 & & 30 QUARTIL & 4,14 & & 30 QUARTIL & 6,00 \\
\hline
\end{tabular}

\section{CONSIDERAÇÕES FINAIS}

Inicialmente, o avaliador formalizou, por meio do instrumento de avaliação, expectativas quase idênticas para as quatorze informações técnicas avaliadas e, segundo o próprio avaliador, essas expectativas se repetem, independente do projeto de engenharia. Observou-se que o avaliador apresentou altas expectativas para os atributos das dimensões de tempo e conteúdo, uma vez que, para o avaliador, os prazos e a qualidade do projeto finalizado sofrem impacto direto desses atributos. Neste sentido, conclui-se que as altas expectativas apresentadas merecem uma atenção especial, a fim de se evitar problemas de satisfação.

De acordo com o avaliador, a dimensão forma não agrega tanto valor às informações técnicas, uma vez que serão processadas e convertidas em desenhos técnicos para os projetos de engenharia. Complementarmente, o avaliador relatou que, para ele, é indiferente a forma desse tipo de informação, desde que seja inteligível.

Os resultados confirmaram a preocupação que se tinha quanto às altas expectativas, uma vez que os gaps resultantes refletiram a insatisfação do avaliador quanto às informações técnicas recebidas da empresa "A". Aliás, os gestores da empresa "A", ao tomarem ciência dos resultados da avaliação, alegaram já esperar pelos gaps negativos apontados na dimensão tempo. No entanto, mostraram-se surpresos com os gaps negativos apontados na dimensão conteúdo e preocupados com as altas expectativas da empresa " $A_{1}$ " com relação às informações. 
Assim, o passo seguinte foi buscar identificar junto às demais empresas terceirizadas, sintomas que pudessem apontar para os mesmos problemas identificados pelo instrumento de avaliação junto à empresa " $A_{1}$ ". A partir desse diagnóstico, os gestores da empresa pesquisada informaram que foi determinado um plano de ação para solucionar os problemas identificados. Segundo os mesmos gestores, o plano de ação foi executado no mês seguinte ao término desta pesquisa, seguindo as prioridades apontadas pelo Quadro 7 e as diretrizes do método de solução de problemas da empresa. Vale ressaltar, que a empresa não forneceu detalhes sobre o plano de ação e o método de solução de problemas; apenas que o problema foi resolvido.

Os gestores da empresa "A" reconheceram que o instrumento de avaliação da QI foi importante para identificar um problema cujas consequências impactariam seriamente sobre a reputação das duas empresas envolvidas no estudo. Segundo os mesmos gestores, havia ainda a possibilidade de adotarem o instrumento de avaliação da QI, a fim de dar continuidade à melhoria de suas informações.

O gestor da empresa terceirizada " $A_{1}$ ", por sua vez, mostrou-se muito satisfeito com o emprego do instrumento de avaliação da QI, pois possibilitou formalizar suas expectativas e percepções quanto às informações que vinha recebendo da empresa "A" (contratante). Segundo o mesmo gestor, isso expandiu a comunicação entre contratante e contratada e abriu a possibilidade de passar a receber informações de melhor qualidade para projetos futuros.

É importante destacar que, após o término desta pesquisa, o instrumento de avaliação da QI teve, além dos ajustes já mencionados nas definições dos atributos de QI, uma redução na escala de 7 para 5 graus. Assim, em pesquisas futuras, pretende-se aferir a efetividade desses ajustes.

Finalmente, pôde-se comprovar que o instrumento desenvolvido não "engessa" a lista de atributos de QI, permitindo que o avaliador exclua ou inclua novos atributos, de acordo com seus critérios de valor. Além disso, mesmo com alguns atributos excluídos, o instrumento mostrou-se confiável, conforme aferido pelo alfa de Cronbach.

Assim, além da proposta de um instrumento de avaliação da qualidade da informação, este trabalho contribuirá também para: (1) a construção do conhecimento no que tange o conceito de qualidade da informação por meio do Revista Produção Online, Florianópolis, SC, v.12, n. 4, p. 1084-1105, out./dez. 2012. 
instrumento de avaliação apresentado; (2) a avaliação de qualquer tipo de fonte geradora de informação, em conseqüência da avaliação da informação produzida pela mesma, e; (3) a gestão da informação, uma vez que o resultado gerado pelo instrumento de avaliação poderá melhor direcionar a manutenção da informação.

\section{REFERÊNCIAS}

BALLOU, D. P.; PAZER, H. L. Modeling data and process quality in multi-input, multioutput information systems. Management Science, v.31, n. 2, p. 530-545, 1985.

BIO, S. R. Sistemas de Informação: um enfoque gerencial. São Paulo: Atlas, 1996.

CERVO, A. L.; BERVIAN, P. A. Metodologia científica. 5. ed. São Paulo: Pearson Prentice Hall, 2002.

CRONBACH, L. J. Coefficient alpha and the internal structure of tests.

Psychometrika, v. 16, n. 3, p. 297-334, 1951.

DAI, Y. S; GAO, Q.; FAN, Z.; KANG, R. G. User perceived quality of online social information services: from the perspective of knowledge management. In:

Proceedings of the 2007 IEEE IEEM, 2007. Proceedings... IEEE IEEM, 2007, p. 482-486.

DELONE, W. H.; MCLEAN, E. R. Information systems success: the quest for the dependent variable. Information Systems Research, v. 3, n. 1, p. 60-95, 1992.

ENGLISH, L. P. Information quality management: The next frontier. In: ASQ'S ANNUAL QUALITY CONGRESS PROCEEDINGS, 2001. Proceedings... ASQ's, 2001, p. 529-533.

FREITAS, A. L. P.; MANHÃES, N. R. C.; COZENDEY, M. I. Emprego do SERVQUAL na avaliação da qualidade de serviços de tecnologia da informação: uma análise experimental. In: ENEGEP, 26., 2006. Fortaleza. Anais... Fortaleza: ENEGEP, 2006.

GIL, A. C. Como elaborar projetos de pesquisa. São Paulo: Atlas, 1987.

GOODHUE, D. L. Understanding user evaluations of information systems.

Management Science, v. 4, n. 12, p. 1827-1844, 1995.

JIANG, J. J.; KLEIN, G.; TESCH, D.; CHEN, H. Closing the user and provider service quality gap: a method for measuring service quality that includes both the user and IS service provider perspectives. Communications of the ACM, v. 46, n. 2, p. 72-76, 2003.

KHAN, B. K.; STRONG, D. M.; WANG, R. Y. Information quality benckmarks: product and service performance. Communications of the ACM, v. 45, n. 4, 2002. 
LEE, Y. W.; STRONG, D. M.; KAHN, B. K.; WANG, R. Y. AIMQ: a methodology for information quality assessment. Information \& Management, v. 40, p. 133-146, 2002.

LI, S.; LIN, B. Accessing information sharing and information quality in supply chain management. Decision Support Systems, v. 42, p. 1641-1656, 2006.

LILLRANK, P. The quality of information. International Journal of Quality \& Reliability Management, v. 20, n. 6, p. 691-703, 2003.

MIGUEL, P. A. C. Estudo de caso na engenharia de produção: estruturação e recomendações para sua condução. Revista Produção, v. 17, n. 1, p. 216-229, 2007.

MILLER, B.; MALLOY, M. A.; MASEK, E.; WILD, C. Towards a framework for managing the information environment. Information, Knowledge, Systems Management, v. 2, n. 4, p. 359-384, 2001.

O'BRIEN, J. A. Sistemas de informação e as decisões gerenciais na era da internet. 2. ed. São Paulo: Saraiva, 2004.

PAIM, I.; NEHMY, R. M. Q.; GUIMARÃES, C. G. Problematização do conceito "Qualidade" da Informação. Perspectivas em Ciência da Informação, Belo Horizonte, v. 1, n. 1, p. 111-119, jan./jun., 1996.

PARASURAMAN, A.; ZEITHAML, V.A.; BERRY, L.L. A conceptual model of services quality and its implication for future research. Journal of Marketing, v. 49, n. 4, p. 41-50, 1985.

PARASURAMAN, A.; ZEITHAML, V. A.; BERRY, L. L. Servqual: a multiple-item scale for measuring consumer perceptions of service quality. Journal of Retailing, $v$. 64, n. 1, p. 12-40, 1988.

PIPINO, L. L.; YANG, W.; WANG, R. Y. Data quality assessment. Communications of the ACM, v. 45, n. 4, p. 211-218, 2002.

SALOMI, G. G. E.; MIGUEL, P. A. C.; ABACKERLI, A. J. SERVQUAL x SERVPERF: Comparação entre instrumentos de avaliação da qualidade de serviços internos.

Gestão \& Produção. São Carlos, v. 12, n. 2, p. 279-293, maio/ago. 2005.

STAIR, R. M.; REYNOLDS, G. W. Princípios de sistemas de informação. 9. ed. São Paulo: Cengage Learning, 2011.

STRONG, D. M.; LEE, Y. W.; WANG, R. Y. Data quality in context.

Communications of the ACM, v. 40, n. 5, p. 103-109, 1997.

WAND, Y.; WANG, R. Y. Data quality dimensions in ontological foundations.

Communications of the ACM, v. 39, n. 11, p. 86-95, 1996. 
WANG, R. W.; STOREY, V.; FIRTH, C. P. A framework of analysis for data quality research. IEEE Transactions on Knowledge and Data Engineering, v. 7, n. 4, p. 623-640, 1995.

WANG, R. W.; STRONG, D. M. Beyond accuracy: what data quality means to data consumers. Journal of Management Information Systems, v. 12, n. 4, p. 5-33, 1996.

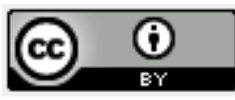

Artigo recebido em 17/05/2011 e aceito para publicação em 23/01/2012. 